\title{
Association of PNPLA3 Polymorphism with Hepatocellular Carcinoma Development and Prognosis in Viral and Non-Viral Chronic Liver Diseases
}

\author{
Apichaya Khlaiphuengsin ${ }^{1}$, Rattanaporn Kiatbumrung ${ }^{1}$, Sunchai Payungporn ${ }^{1}$, \\ Nutcha Pinjaroen ${ }^{2}$, Pisit Tangkijvanich ${ }^{1 *}$
}

\begin{abstract}
Background: The aim of this study was to evaluate any association between a single nucleotide polymorphism (SNP) in the patatin-like phospholipase domain containing 3 (PNPLA3) (rs738409, C>G) and the development and prognosis in patients with hepatocellular carcinoma (HCC). Materials and Methods: Two hundred heathy controls and $388 \mathrm{HCC}$ cases were included: 211 with $\mathrm{HBV}, 98$ patients with $\mathrm{HCV}, 29$ with alcoholic steatohepatitis (ASH) and 52 with non-alcoholic steatohepatitis (NASH). The SNP was determined by real-time PCR based on TaqMan assays. Results: The prevalence of rs738409 genotypes CC, CG and GG in controls was 91 (45.5\%), $88(44.0 \%)$, and $21(10.5 \%)$, respectively, while the corresponding genotypes in all patients with HCC was 158 $(40.7 \%), 178(45.9 \%)$, and $52(13.4 \%)$. The GG genotype had significantly higher distribution in patients with ASH/NASH-related HCC compared with controls $(\mathrm{OR}=2.34,95 \% \mathrm{CI}=1.16-4.71, \mathrm{P}=\mathbf{0 . 0 1 8})$, and viral-related HCC cases $(\mathrm{OR}=2.15,95 \% \mathrm{CI}=1.13-4.08, \mathrm{P}=0.020)$. However, the frequency of the $\mathrm{GG}$ genotype was similar between controls and patients with viral-related HCC. At initial diagnosis, HBV-related HCC were larger and at more advanced BCLC stage than the other HCC groups. There were no significant differences between the GG and non-GG groups regarding clinical characteristics, tumor stage and overall survival. Conclusions: These data suggest an influence of the PNPLA3 polymorphism on the occurrence of HCC in patients with ASH/NASH but not among those with chronic viral hepatitis. However, the polymorphism was not associated with the prognosis of HCC.
\end{abstract}

Keywords: PNPLA3 - HBV - HCV - ASH - NASH - HCC development - prognosis

Asian Pac J Cancer Prev, 16 (18), 8377-8382

\section{Introduction}

Hepatocellular carcinoma (HCC) is one of the most frequently causes of cancer-related death worldwide (Nault, 2014). The prevalence of HCC is geographically variable with the highest frequencies observed in subSaharan Africa and Southeast Asia (Gao et al., 2012). $\mathrm{HCC}$ is mostly found in subjects with cirrhosis caused by chronic liver diseases (CLD). Major risk factors of $\mathrm{HCC}$ in Thailand are chronic hepatitis B virus (HBV) or chronic hepatitis $\mathrm{C}$ virus (HCV) infection, which account for approximately $80 \%$ of all cases (Tangkijvanich et al., 1999). Alcoholic steatohepatitis (ASH) and nonalcoholic steatohepatitis (NASH)-associated cirrhosis also represent common etiological factors for $\mathrm{HCC}$. In addition, host genetic variants, including single nucleotide polymorphisms (SNPs), have been showed to be associated with the development and progression of HCC (Jin et al., 2011).

In 2008, genome-wide association study (GWAS) has identified an association between rs738409 (C>G) SNP and hepatic steatosis content (Yuan et al., 2008). This SNP is located in the patatin-like phospholipase domain containing 3 (PNPLA3) or adiponutrin gene encoding for a protein of $53 \mathrm{kDa}$ with 481 amino acids and is induced by lipogenesis steroid regulatory element binding protein-1c (Huang et al., 2010). The sequence variation of rs738409 $(\mathrm{C}>\mathrm{G})$ is responsible for an amino acid change at position 148 from isoleucine to methionine (Ile148Met). It has been demonstrated that this SNP is related to the impairment of hepatic triglyceride hydrolysis, resulting the accumulation of triglycerides in the hepatocytes (He et al., 2010). Recent studies have shown an association between rs738409 and HCC development in NASH (Romeo et al., 2008; Valenti et al., 2013; Liu et al., 2014) and ASH (Nischalke et al., 2011; Stickel et al., 2011; Trepo et al., 2012), suggesting a carcinogenic effect by modulating lipid metabolism. However, it is not clear whether this polymorphism affects HCC development in patients with chronic viral hepatitis (Singal et al., 2014). Thus, the purpose of this study was

${ }^{1}$ Department of Biochemistry Research Unit of Hepatitis and Liver Cancer, ${ }^{2}$ Department of Radiology, Faculty of Medicine, Chulalongkorn University, Bangkok, Thailand *For correspondence: pisittkvn@yahoo.com 
Apichaya Khlaiphuengsin et al

to investigate the association between rs738409 (C>G) and HCC development and prognosis in Thai patients with viral and non-viral CLD.

\section{Materials and Methods}

Patients and samples

Blood samples for the detection of rs738409 SNP were obtained from patients who were diagnosed with $\mathrm{HCC}$ for the first time at King Chulalongkorn Memorial Hospital (Bangkok, Thailand) during 2011-2014. The diagnosis of HCC was based on typical imaging studies and/or histopathology according to American Association for the Study of Liver Diseases (AASLD) guideline (Bruix and Sherman, 2011). Diagnostic criteria of HCC by imaging modalities were based on reports of focal lesions with hyperattenuation at the arterial phase, hypoattenuation at the portal phase in dynamic imaging studies. In cases without typical imaging features liver biopsy/fine needle aspiration was performed to confirm the diagnosis of HCC.

The clinical data of patients with HCC at initial diagnosis were collected, and HCC staging was classified into stages 0 and A to D based on Barcelona Clinic Liver Cancer staging system (BCLC) (Llovet et al., 2008). The control groups included healthy volunteers with no apparent liver disease. The study was approved by the Ethics Committee, Faculty of Medicine, Chulalongkorn University. Blood samples were obtained at initial presentation and were separated by centrifugation and stored at $-70^{\circ} \mathrm{C}$ until tested.

DNA preparation and genetic analysis

Genomic DNA was extracted from $100 \mu \mathrm{l}$ peripheral blood mononuclear cells (PBMCs) using phenolchloroform-isoamyl alcohol isolation method as described previously (Sopipong et al., 2013). The quality of DNA was measured using spectrophotometer (NanoDrop 2000c, Thermo Scientific).

PNPLA3 SNP (rs738409) was genotyped using real-time PCR protocol based on TaqMan assays. The reaction was performed including $4 \mu \mathrm{l}$ of $2.5 \mathrm{X}$ master mix (5 PRIME, Germany), $0.25 \mu 1$ of $40 \mathrm{X}$ primers and probes mixture (TaqMan SNP Genotyping Assay (assay ID:C_7241_10), Applied Biosystems, USA), 50-100 ng of genomic DNA and nuclease-free water to the final volume of $10 \mu \mathrm{l}$. The real-time PCR condition was performed in StepOne Plus Real-time PCR system (Applied Biosystems, USA) according to the manufacturer's protocol. Briefly, initial denaturation was hold at $95^{\circ} \mathrm{C}$ for $10 \mathrm{~min}$, followed by 50 cycles of amplification including denaturation at $92^{\circ} \mathrm{C}$ for $10 \mathrm{sec}$, and annealing/extension at $60^{\circ} \mathrm{C}$ for 1 min. Fluorescent signals (FAM and VIC) were acquired at the end of each cycle. Positive and negative controls were included in each experiment in order to ensure appropriate data interpretation. Allelic discrimination plot was analyzed using StepOne TM software (version 2.2, Applied Biosystems).

Table 1. Baseline Characteristics of Patients with HCC and Controls

\begin{tabular}{|c|c|c|c|c|c|c|}
\hline & \multirow{2}{*}{$\begin{array}{l}\text { Control } \\
(n=200)\end{array}$} & \multirow{2}{*}{$\begin{array}{c}\text { HBV } \\
(n=211)\end{array}$} & \multirow{2}{*}{$\begin{array}{l}\mathrm{HCV} \\
(\mathrm{n}=98)\end{array}$} & \multirow{2}{*}{$\begin{array}{c}\text { ASH/NASH } \\
(n=79)\end{array}$} & \multicolumn{2}{|c|}{$P$ values } \\
\hline & & & & & $\begin{array}{c}\text { Compared with } \\
\text { ASH/NASH }\end{array}$ & $\begin{array}{c}\text { Compared with } \\
\text { Control }\end{array}$ \\
\hline Age (years) a & $47.5 \pm 5.2$ & $58.1 \pm 11.0$ & $59.7 \pm 8.1$ & $66.5 \pm 11.4$ & $\begin{array}{l}<0.001^{+} \\
<0.001^{++}\end{array}$ & $\begin{array}{l}<0.001^{+} \\
<0.001^{++} \\
<0.001^{+++}\end{array}$ \\
\hline $\operatorname{Sex}(\%)$ & & & & & & $<0.001^{+}$ \\
\hline male & $111(55.5 \%)$ & $186(88.2 \%)$ & $78(79.6 \%)$ & $62(78.5 \%)$ & $0.037^{+}$ & $<0.001^{++}$ \\
\hline female & $89(45.5 \%)$ & $25(11.8 \%)$ & $20(20.4 \%)$ & $17(21.5 \%)$ & $0.857^{++}$ & $<0.001^{+++}$ \\
\hline $\mathrm{TB}(\mathrm{mg} / \mathrm{dL}) \mathrm{a}$ & & $1.2 \pm 1.0$ & $1.8 \pm 2.9$ & $1.7 \pm 3.5$ & $\begin{array}{l}0.252^{+} \\
0.866^{++}\end{array}$ & \\
\hline Albumin $(\mathrm{mg} / \mathrm{dL})$ a & & $3.6 \pm 0.6$ & $3.3 \pm 0.6$ & $3.5 \pm 0.6$ & $\begin{array}{l}0.566^{+} \\
0.019^{++}\end{array}$ & \\
\hline $\operatorname{ALT}(\mathrm{IU} / \mathrm{L}) \mathrm{a}$ & & $67.3 \pm 80.9$ & $79.1 \pm 66.0$ & $62.3 \pm 81.3$ & $\begin{array}{l}0.642^{+} \\
0.132^{++}\end{array}$ & \\
\hline $\operatorname{ALP}(\mathrm{mg} / \mathrm{L}) \mathrm{a}$ & & $169.0 \pm 132.8$ & $158.0 \pm 279.3$ & $146.3 \pm 93.9$ & $\begin{array}{l}0.164^{+} \\
0.722^{++}\end{array}$ & \\
\hline Child-Puge score (\%) & & & & & $0.298^{+}$ & \\
\hline A & & $163(77.6 \%)$ & $65(66.3 \%)$ & $59(74.7 \%)$ & $0.423^{++}$ & \\
\hline B & & $46(21.9 \%)$ & $31(31.6 \%)$ & $18(22.8 \%)$ & & \\
\hline $\mathrm{C}$ & & $1(0.5 \%)$ & $2(2.0 \%)$ & $2(2.5 \%)$ & & \\
\hline BCLC stage (\%) & & & & & $<0.005^{+}$ & \\
\hline $0-\mathrm{A}$ & & $50(23.7 \%)$ & $39(39.8 \%)$ & $24(30.4 \%)$ & $0.206^{++}$ & \\
\hline B & & $84(39.8 \%)$ & $39(39.8 \%)$ & $42(53.2 \%)$ & & \\
\hline C-D & & $77(36.5 \%)$ & $20(20.4 \%)$ & $13(16.4 \%)$ & & \\
\hline Tumor size $(\mathrm{cm})$ a & & $7.4 \pm 5.8$ & $4.6 \pm 3.7$ & $6.1 \pm 4.6$ & $\begin{array}{l}0.055^{+} \\
0.018^{++}\end{array}$ & \\
\hline PNPLA3 rs738409 (\%) & & & & & $0.045^{+}$ & $0.413^{+}$ \\
\hline $\mathrm{CC}$ & $91(45.5 \%)$ & $83(39.3 \%)$ & $46(46.9 \%)$ & $29(36.7 \%)$ & $0.237^{++}$ & $0.690^{++}$ \\
\hline CG & $88(44.0 \%)$ & $106(50.2 \%)$ & $39(39.8 \%)$ & $33(41.8 \%)$ & & $0.047^{+++}$ \\
\hline GG & $21(10.5 \%)$ & $22(10.4 \%)$ & $13(13.3 \%)$ & $17(21.5 \%)$ & & \\
\hline
\end{tabular}

${ }^{\mathrm{a}}:\left(\right.$ mean \pm SD), ALT : Alanine transaminase, TB : Total bilirubin, ALP : Alkaline phosphatase; ${ }^{+}=\mathrm{HBV},{ }^{++}=\mathrm{HCV},{ }^{++}=\mathrm{ASH} / \mathrm{NASH}$ 
Statistical analysis

Comparisons between groups were analyzed by Student's t-test when appropriate for quantitative variables (http://graphpad.com/quickcalcs/ttest1.cfm). Hardy-Weinberg equilibrium (HWE) was tested using Pearson's Chi-square as implemented in online software (http://ihg.gsf.de/ihg/snps.html). Associations of different genetic models with HCC risk were assessed under allelic, additive, dominant and recessive models. Odd ratios (ORs) with 95\% confidence intervals (CIs) between each group were determined using MedCalc statistical software version 13.3.3 (http://www.medcalc.org/calc/odds_ratio. php). Survival analysis was determined by using the Kaplan-Meier method and compared with the log-rank test. The P-values less than 0.05 were considered to be statistically significant.

\section{Results}

\section{Patient characteristics}

A total of 200 healthy controls and 388 patients with HCC were included in the study. The etiologies of HCC were as the followings: 211 patients with HBV-related $\mathrm{HCC}$ (positive for hepatitis B surface antigen; HBsAg), 98 with HCV-related HCC (positive for anti-HCV), 29 and 52 patients were ASH- and NASH-related HCC, respectively. Since a relatively small proportion of patients with ASH- and NASH-related HCC, we grouped these patients together as ASH/NASH-related HCC for statistical analysis. The baseline clinical characteristics of patients according to underlying etiologies are summarized in Table 1.

Patients with ASH/NASH-related HCC were significantly older than those with viral-related HCC and controls. There was also significant difference in gender distribution between groups, as controls and HBV-related $\mathrm{HCC}$ had higher prevalence of female. At the initial diagnosis, HBV-related HCC had larger tumor size and more advanced BCLC staging than HCV-and ASH/ NASH-related HCC.

Association between rs 738409 SNP and HCC occurrence

The genotype frequencies of rs738409 were not deviated from Hardy-Weinberg Equilibrium among study participants $(\mathrm{P}=0.880)$. The prevalence of $\mathrm{rs} 738409$ genotypes CC, CG and GG in controls was 91 (45.5\%), $88(44.0 \%)$, and $21(10.5 \%)$, respectively, while the corresponding genotypes in all patients with HCC was $158(40.7 \%), 178(45.9 \%)$, and $52(13.4 \%)$, respectively. Of note, the distribution of rs 738409 genotypes was similar between controls and all patients with HCC. When stratified by underlying etiologies, the distribution of rs738409 genotypes was comparable between controls and patients with $\mathrm{HBV}$ - and HCV-related $\mathrm{HCC}(\mathrm{P}=0.413$

Table 2. Genotype and Allele Frequencies of SNP rs738409 in Patients with HCC and Controls

\begin{tabular}{|c|c|c|c|c|c|c|c|c|c|c|}
\hline \multirow{2}{*}{ PNPLA3 } & \multirow{2}{*}{$\begin{array}{r}\text { HBV } \\
(\mathrm{n}=211)\end{array}$} & \multirow{2}{*}{$\begin{array}{l}\mathrm{HCV} \\
(\mathrm{n}=98)\end{array}$} & \multirow{2}{*}{$\begin{array}{c}\text { ASH/NASH } \\
(\mathrm{n}=79)\end{array}$} & \multirow{2}{*}{$\begin{array}{l}\text { Control } \\
(\mathrm{n}=200)\end{array}$} & \multicolumn{2}{|c|}{ HBV vs. Controls } & \multicolumn{2}{|c|}{ HCV vs. Controls } & \multicolumn{2}{|c|}{ ASH/NASH vs. Controls } \\
\hline & & & & & ) OR $(95 \% \mathrm{CI})$ & $P$ values & OR $(95 \% \mathrm{CI})$ & $P$ values & OR (95\% CI) & $P$ values \\
\hline \multicolumn{11}{|c|}{ Allelic model } \\
\hline Major (C) & 272 & 131 & 91 & 270 & 1 & - & 1 & - & 1 & - \\
\hline $\operatorname{Minor}(G)$ & 150 & 65 & 67 & 130 & $1.15(0.8$ & 0.357 & $1.03(0$. & 0.871 & $1.53(1$ & 0.028 \\
\hline \multicolumn{11}{|c|}{ Additive model } \\
\hline $\mathrm{CC}$ & 83 & 46 & 29 & 91 & 1 & - & 1 & - & 1 & - \\
\hline $\mathrm{CG}$ & 106 & 3 & $3 ?$ & 88 & $1.32(0$. & 0.184 & $0.88(0$. & 0.6 & 1.18 & 0.581 \\
\hline GG & 22 & 13 & 17 & 21 & $1.15(0.59-2.24)$ & 0.684 & $1.22(0.56-2.66)$ & 0.609 & $2.54(1.18-5.45)$ & 0.017 \\
\hline \multicolumn{11}{|c|}{ Dominant model } \\
\hline $\mathrm{CC}$ & 83 & 46 & 29 & 91 & 1 & - & 1 & - & 1 & - \\
\hline $\mathrm{CG}+\mathrm{GG}$ & 128 & 52 & 50 & 109 & $1.29(0.87-1.91)$ & 0.207 & $0.94(0.58-1.53)$ & 0.815 & $1.44(0.84-2.46)$ & 0.183 \\
\hline \multicolumn{11}{|c|}{ Recessive model } \\
\hline $\mathrm{CC}+\mathrm{CG}$ & 189 & 85 & 62 & 179 & 1 & - & 1 & - & 1 & - \\
\hline GG & 22 & 13 & 17 & 21 & $0.99(0.53-1.87)$ & 0.981 & $1.30(0.62-2.73)$ & 0.482 & $2.34(1.16-4.71)$ & 0.018 \\
\hline
\end{tabular}

Table 3. Genotype and allele Frequencies of SNP rs738409 in Relation to Underlying Etiologies of HCC

\begin{tabular}{|c|c|c|c|c|c|c|c|c|c|}
\hline \multirow[t]{2}{*}{ PNPLA3 } & \multirow{2}{*}{$\begin{array}{c}\text { HBV } \\
(n=211)\end{array}$} & \multirow{2}{*}{$\begin{array}{l}\mathrm{HCV} \\
(\mathrm{n}=98)\end{array}$} & \multirow{2}{*}{$\begin{array}{c}\text { ASH/NASH } \\
(\mathrm{n}=79)\end{array}$} & \multicolumn{2}{|c|}{ ASH/NASH vs. HBV } & \multicolumn{2}{|c|}{ ASH/NASH vs. HCV } & \multicolumn{2}{|c|}{ Non-Viral vs. Viral } \\
\hline & & & & OR $(95 \% \mathrm{CI})$ & $P$ values & OR $(95 \% \mathrm{CI})$ & $P$ values & OR $(95 \% \mathrm{CI})$ & $P$ values \\
\hline \multicolumn{10}{|l|}{ Allelic model } \\
\hline Major (C) & 272 & 131 & 91 & 1.00 & - & 1 & - & 1 & - \\
\hline $\operatorname{Minor}(\mathrm{G})$ & 150 & 65 & 67 & $1.34(0.92-1.90)$ & 0.1 & $1.48(0.96-2.29)$ & 0.074 & $1.38(0.97-1.97)$ & 0.076 \\
\hline \multicolumn{10}{|c|}{ Additive model } \\
\hline $\mathrm{CC}$ & 83 & 46 & 29 & 1 & - & 1 & - & 1 & - \\
\hline CG & 106 & 39 & 33 & $0.89(0.50-1.58)$ & 0.694 & $1.34(0.70-2.59)$ & 0.38 & $1.01(0.58-1.76)$ & 0.965 \\
\hline GG & 22 & 13 & 17 & $2.21(1.03-4.73)$ & 0.041 & $2.07(0.88-4.90)$ & 0.096 & $2.16(1.07-4.38)$ & 0.032 \\
\hline \multicolumn{10}{|c|}{ Dominant model } \\
\hline $\mathrm{CC}$ & 83 & 46 & 29 & 1 & - & 1 & - & 1 & - \\
\hline $\mathrm{CG}+\mathrm{GG}$ & 128 & 52 & 50 & $1.12(0.66-1.91)$ & 0.683 & $1.53(0.83-2.79)$ & 0.172 & $1.24(0.74-2.06)$ & 0.416 \\
\hline \multicolumn{10}{|c|}{ Recessive model } \\
\hline $\mathrm{CC}+\mathrm{CG}$ & 189 & 85 & 62 & 1 & - & 1 & - & 1 & - \\
\hline GG & 22 & 13 & 17 & $2.36(1.18-4.72)$ & 0.016 & $1.79(0.81-3.96)$ & 0.149 & $2.15(1.13-4.08)$ & 0.020 \\
\hline
\end{tabular}


Apichaya Khlaiphuengsin et al

and $\mathrm{P}=0.690$, respectively). In contrast, its prevalence was significantly different between patients with ASH/NASHrelated HCC and controls $(\mathrm{P}=0.047)$, as well as between patients with $\mathrm{ASH} / \mathrm{NASH}$-related $\mathrm{HCC}$ and $\mathrm{HBV}$-related HCC $(\mathrm{P}=0.045)$. However, no significant difference in rs738409 genotype distribution was found between patients with ASH/NASH-related HCC and HCV-related HCC $(\mathrm{P}=0.237)$ (Table 1).

Table 2 demonstrates genotype and allele frequencies of SNP rs738409 of patients with HCC compared with controls. The frequencies of $\mathrm{C}$ allele in patients with HCC and controls were $63.7 \%$ and $67.5 \%$, respectively, whereas the frequencies of $\mathrm{G}$ allele were $36.3 \%$ and $32.5 \%$, respectively. The frequency of $\mathrm{G}$ allele was comparable between patients with viral-related HCC and controls. However, $\mathrm{G}$ allele significantly higher in patients with ASH/NASH-related HCC compared with controls $(\mathrm{OR}=1.53,95 \% \mathrm{CI}=1.05-2.23, \mathrm{P}=0.028)$, indicating that this allele might associate with an increased risk of ASH/ NASH-related HCC. We also found similar results under additive $(\mathrm{OR}=2.54,95 \% \mathrm{CI}=1.18-5.45, \mathrm{P}=0.027)$ and recessive models $(\mathrm{OR}=2.34,95 \% \mathrm{CI}=1.16-4.71, \mathrm{P}=0.018)$.

Among patients with $\mathrm{HCC}$, the $\mathrm{G}$ allele showed a

Table 4. Clinical Characteristics of Patients with HCC Carried CC/CG and GG Genotypes

\begin{tabular}{|c|c|c|c|}
\hline & \multicolumn{2}{|c|}{ rs738409 } & \multirow[t]{2}{*}{$P$ values } \\
\hline & $\begin{array}{r}\mathrm{CC} \text { or } \mathrm{CG} \\
\mathrm{N}=336\end{array}$ & $\begin{array}{r}\mathrm{GG} \\
\mathrm{N}=52\end{array}$ & \\
\hline Age (years) & $60.0 \pm 10.9$ & $61.8 \pm 10.7$ & 0.257 \\
\hline \multicolumn{4}{|l|}{$\operatorname{Sex}(\%)$} \\
\hline male & $284(84.5 \%)$ & $42(80.8 \%)$ & 0.831 \\
\hline female & $52(15.5 \%)$ & $10(19.2 \%)$ & \\
\hline TB (mg/dL) & $1.3 \pm 1.8$ & $2.1 \pm 4.1$ & 0.21 \\
\hline Albumin (mg/dL) & $3.5 \pm 0.6$ & $3.4 \pm 0.6$ & 0.144 \\
\hline ALT (IU/L) & $69.2 \pm 77.5$ & $69.2 \pm 78.5$ & 0.996 \\
\hline $\operatorname{ALP}(\mathrm{mg} / \mathrm{L})$ & $163.9 \pm 184.7$ & $147.1 \pm 105.2$ & 0.523 \\
\hline \multicolumn{3}{|c|}{ Child-Puge score (\%) } & 0.213 \\
\hline A & $249(74.3 \%)$ & $38(73.1 \%)$ & \\
\hline B & $83(24.8 \%)$ & $12(23.1 \%)$ & \\
\hline $\mathrm{C}$ & $3(0.9 \%)$ & $2(3.8 \%)$ & \\
\hline \multicolumn{3}{|l|}{ BCLC stage (\%) } & 0.452 \\
\hline $0-A$ & $97(28.9 \%)$ & $16(30.8 \%)$ & \\
\hline $\mathrm{B}$ & $140(41.7 \%)$ & $25(48.1 \%)$ & \\
\hline C-D & $99(29.5 \%)$ & $11(21.1 \%)$ & \\
\hline Tumor size $(\mathrm{cm})$ & $6.5 \pm 5.2$ & $5.5 \pm 4.6$ & 0.185 \\
\hline
\end{tabular}

A

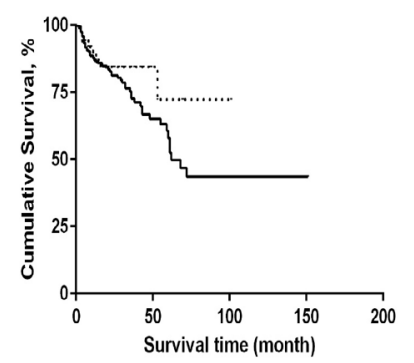

B

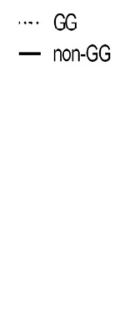

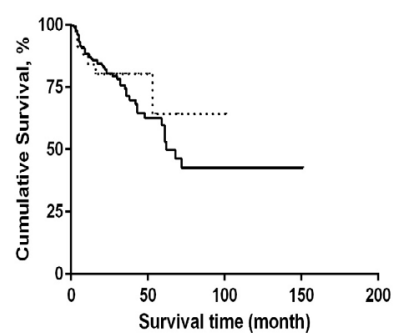

trend toward an association with $\mathrm{ASH} / \mathrm{NASH}$-related HCC compared with HBV-related HCC, although the difference did not reach statistically significant $(\mathrm{OR}=1.34$, 95\% $\mathrm{CI}=0.92-1.90, \mathrm{P}=0.100)$. However, this association was statistically significant under additive $(\mathrm{OR}=2.21,95 \%$ $\mathrm{CI}=1.03-4.73, \mathrm{P}=0.041)$ and recessive models $(\mathrm{OR}=2.36$, $95 \% \mathrm{CI}=1.18-4.72, \mathrm{P}=0.016)$. When compared ASH/ NASH-related HCC with viral-related HCC, we observed the same trend of association under the $\mathrm{G}$ allele $(\mathrm{OR}=1.38$, 95\% $\mathrm{CI}=0.97-1.97, \mathrm{P}=0.076)$, additive $(\mathrm{OR}=2.16,95 \%$ $\mathrm{CI}=1.07-4.38, \mathrm{P}=0.032)$ and recessive models $(\mathrm{OR}=2.15$, 95\% CI=1.13-4.08, $\mathrm{P}=0.020$ ) (Table 3).

Correlation of rs 738409 SNP with disease characteristics and survival

Clinical characteristics of all patients with $\mathrm{HCC}$ were compared between rs738409 GG and non-GG (CC and $\mathrm{CG})$ genotypes. The correlations between groups and various clinical parameters listed in Table 4 were analyzed. There were no significant differences between the two groups regarding age, sex distribution, biochemical blood tests, Child-Puge score, tumor size and BCLC staging. Similar observations were found after stratification by viral and non-viral HCC (data not shown).

The potential prognostic value of rs 738409 was also analyzed. The overall survival of HCC patients carried $\mathrm{GG}$ and non-GG genotypes were not different $(\mathrm{P}=0.182$ by $\log$ rank test). Similar observations were found after stratification by viral and non-viral HCC $(\mathrm{P}=0.549$ and 0.182 by $\log$ rank test, respectively) (Figure 1A-1C).

\section{Discussion}

HCC is a strongly heterogeneous disease associated with various risk factors including chronic $\mathrm{HBV}$ and $\mathrm{HCV}$ infection, alcohol intake and metabolic syndrome (Nault, 2014). Although epidemiological and biological features associated with HCC occurrence are well recognized, host genetic factors that may also play an important role in hepatic carcinogenesis remain uncertain. In this study, we retrospectively investigated the impact of PNPLA3 polymorphism in HCC development associated with viral and non-viral CLD. Interestingly, we found that the polymorphism influenced an increased HCC risk only in patients with ASH/NASH-related CLD but not in patients with chronic viral hepatitis. Specifically, the prevalence of GG genotype was comparable between patients with

Figure 1. Association of SNP rs738409 (GG and non-GG genotypes) with Survival Rates (A) all Patients with HCC (B) Viral-related HCC (C) ASH/NASH-related HCC 
viral-related HCC and controls. On the other hand, patients with ASH/NASH-related HCC had a more than twofold frequency of GG genotype compared to those with viralrelated $\mathrm{HCC}$ and controls. These findings are in line with previous observations that PNPLA3 polymorphism is associated with susceptibility to HCC in ASH and NASH (Trepo et al., 2012; Liu et al., 2014) and may indicate differential mechanisms of hepatic carcinogenesis in relation to underlying etiology of CLD.

PNPLA3, a trans-membrane protein highly expressed in the liver, belongs to a novel class of patatin-like phospholipase domain family proteins. Although the function of PNPLA3 in vivo is currently unknown, in vitro studies have demonstrated that PNPLA3 is able to act as a transacylase that synthesizes intracellular triglycerides by transferring acyl groups (Jenkins et al., 2004). Recent data have also showed that wild type PNPLA3 has a lipase activity and Ile148Met substitution causes a loss of enzyme activity (Pingitore et al., 2014). In animal model, recent evidence from a knock-in mice study has demonstrated that the Ile148Met variant of adiponutrin directly results in the accumulation of hepatic steatosis when fed a high-sucrose diet (Smagris et al., 2015). In fact, the effect of PNPLA3 polymorphism has been shown to be strongly and independently associated with percentage of hepatic fat content in patients of various CLD including ASH, NASH and chronic viral hepatitis (Sookoian et al., 2009; Stickel et al., 2011; Trepo et al., 2011; Vigano et al., 2013; Salameh et al., 2015). These data suggest that PNPLA3 influences the severity of hepatic steatosis regardless of the underlying etiologies of CLD.

Despite its strong influence on hepatic steatosis of various etiologies, a significant association between PNPLA3 polymorphism and the development of HCC has been consistently found only among patients with fatty liver diseases, including ASH and NASH (Trepo et al., 2012; Guyot et al., 2013; Takeuchi et al., 2013; Liu et al., 2014; Trepo et al., 2014). Indeed, both ASH and NASH have rather similar disease spectrums, starting with fatty liver change followed by inflammation, progressive fibrosis, and finally cirrhosis. Moreover, both ASH and NASH appear to share common pathogenic mechanisms including oxidative stress and endotoxin mediated cytokine release(Day, 2006). Accordingly, it seems likely that genetic factors such as PNPLA3 polymorphism predisposing an individual to ASH may play a role in determining the risk of NASH. Taken together, current evidence have supported the notion that PNPLA3 polymorphism is an independent risk factor for HCC susceptibility in fatty liver diseases. Interestingly, in spite of their association with the development of ASH/ NASH related HCC, the correlation of the SNP with clinical characteristics and the prognostic significance was not established in this report. In contrast, previous studies demonstrated that survival free of liver transplantation was significantly lower in patients with ASH when carrying one or two G allele compared with wild-type (Friedrich et al., 2014).

Hepatic steatosis is frequently observed in patients with chronic HCV infection and is influenced by several factors, such as alcohol consumption, metabolic syndrome and HCV genotype 3 (Rubbia-Brandt et al., 2000). It has been shown that hepatic steatosis in chronic HCV infection is associated with more severe liver damage, advanced fibrosis and poor response to antiviral therapy (Patton et al., 2004). Interestingly, although PNPLA3 polymorphism has been related to hepatic steatosis in patients with $\mathrm{HCV}$ infection, its association with HCC development is less clear with conflicting results. Some studies have demonstrated that the GG genotype effect the risk of HCC development (Falleti et al., 2011; Sato et al., 2014), while most other studies have reported no such association (Nischalke et al., 2011; Guyot et al., 2013; Friedrich et al., 2014). For patients with HBV infection, recent data reported that PNPLA3 polymorphism was independently associated with hepatic steatosis, but not with advanced fibrosis and HCC development (Vigano et al., 2013; Brouwer et al., 2015; Zampino et al., 2015). As a result, these data, as well as our report, suggest an apparent weaker or even no effect of PNPLA3 polymorphism on the risk of $\mathrm{HCC}$ in patients with chronic viral hepatitis as compared to those with fatty liver diseases.

Our study has some limitations such as a retrospective cross-sectional study which included small sample sizes of non-viral-related HCC. This limitation might reflect the fact that most HCC patients in Thai populations are related to chronic viral hepatitis. In addition, this study was conducted in a tertiary hospital and selection bias of patients might be possible. Our study also included only Thai patients, which might not be applicable to other ethnic populations. However, other studies in Asia and Western countries have also shown similar observation; hence, this effect was considered to be negligible.

In conclusion, our study showed that PNPLA3 polymorphism was associated with $\mathrm{HCC}$ risk in patients with fatty liver diseases, but was not related to those with chronic viral hepatitis. In addition, no significant association was observed between the prognosis of HCC and PNPLA3 SNP genotypes, regardless of the etiological factors of HCC. Thus, PNPLA3 genotyping may offer the potential to identify individuals at increased risk of developing ALD- and NAFLD-related HCC and provide the opportunity for targeted interventions to prevent the cancer. Further prospective studies are required to confirm these observations and to evaluate the mechanism of PNPLA3 influenced HCC development in patients with fatty liver diseases.

\section{Acknowledgements}

This study was supported by the Ratchadaphiseksomphot Endowment Fund of Chulalongkorn University (CU-57001-HR). We would like to thank all the staff of Research Unit of Hepatitis and Liver Cancer, Faculty of Medicine, Chulalongkorn University.

\section{References}

Brouwer WP, van der Meer AJ, Boonstra A, et al (2015). The impact of PNPLA3 (rs738409 C $>$ G) polymorphisms on liver histology and long-term clinical outcome in chronic hepatitis B patients. Liver Int, 35, 438-47. 
Apichaya Khlaiphuengsin et al

Bruix J, Sherman M (2011). Management of hepatocellular carcinoma: an update. Hepatology, 53, 1020-2.

Day CP (2006). From fat to inflammation. Gastroenterology, 130, 207-10.

Falleti E, Fabris C, Cmet S, et al (2011). PNPLA3 rs738409C/G polymorphism in cirrhosis: relationship with the aetiology of liver disease and hepatocellular carcinoma occurrence. Liver Int, 31, 1137-43.

Friedrich K, Wannhoff A, Kattner S, et al (2014). PNPLA3 in end-stage liver disease: alcohol consumption, hepatocellular carcinoma development, and transplantation-free survival. J Gastroenterol Hepatol, 29, 1477-84.

Gao J, Xie L, Yang WS, et al (2012). Risk factors of hepatocellular carcinoma--current status and perspectives. Asian Pac J Cancer Prev, 13, 743-52.

Guyot E, Sutton A, Rufat P, et al (2013). PNPLA3 rs738409, hepatocellular carcinoma occurrence and risk model prediction in patients with cirrhosis. J Hepatol, 58, 312-8.

He S, McPhaul C, Li JZ, et al (2010). A sequence variation (I148M) in PNPLA3 associated with nonalcoholic fatty liver disease disrupts triglyceride hydrolysis. J Biol Chem, 285, 6706-15.

Huang Y, He S, Li JZ, et al (2010). A feed-forward loop amplifies nutritional regulation of PNPLA3. Proc Natl Acad Sci U S A, 107, 7892-7.

Jenkins CM, Mancuso DJ, Yan W, et al (2004). Identification, cloning, expression, and purification of three novel human calcium-independent phospholipase A2 family members possessing triacylglycerol lipase and acylglycerol transacylase activities. J Biol Chem, 279, 48968-75.

Jin F, Xiong WJ, Jing JC, et al (2011). Evaluation of the association studies of single nucleotide polymorphisms and hepatocellular carcinoma: a systematic review.J Cancer Res Clin Oncol, 137, 1095-104.

Liu YL, Patman GL, Leathart JB, et al (2014). Carriage of the PNPLA3 rs738409 $\mathrm{C}>\mathrm{G}$ polymorphism confers an increased risk of non-alcoholic fatty liver disease associated hepatocellular carcinoma. J Hepatol, 61, 75-81.

Llovet JM, Di Bisceglie AM, Bruix J, et al (2008). Design and endpoints of clinical trials in hepatocellular carcinoma. $J$ Natl Cancer Inst, 100, 698-711.

Nault JC (2014). Pathogenesis of hepatocellular carcinoma according to aetiology. Best Pract Res Clin Gastroenterol, 28, 937-47.

Nischalke HD, Berger C, Luda C, et al (2011). The PNPLA3 rs738409 148M/M genotype is a risk factor for liver cancer in alcoholic cirrhosis but shows no or weak association in hepatitis C cirrhosis. PLoS One, 6, 27087.

Patton HM, Patel K, Behling C, et al (2004). The impact of steatosis on disease progression and early and sustained treatment response in chronic hepatitis C patients. J Hepatol, 40, 484-90.

Pingitore P, Pirazzi C, Mancina RM, et al (2014). Recombinant PNPLA3 protein shows triglyceride hydrolase activity and its I148M mutation results in loss of function. Biochim Biophys Acta, 1841, 574-80.

Romeo S, Kozlitina J, Xing C, et al (2008). Genetic variation in PNPLA3 confers susceptibility to nonalcoholic fatty liver disease. Nat Genet, 40, 1461-5.

Rubbia-Brandt L, Quadri R, Abid K, et al (2000). Hepatocyte steatosis is a cytopathic effect of hepatitis $\mathrm{C}$ virus genotype 3. J Hepatol, 33, 106-15.

Salameh H, Raff E, Erwin A, et al (2015). PNPLA3 Gene polymorphism is associated with predisposition to and severity of alcoholic liver disease. The American journal of gastroenterology, 110, 846-56.

Sato M, Kato N, Tateishi R, et al (2014). Impact of PNPLA3 polymorphisms on the development of hepatocellular carcinoma in patients with chronic hepatitis $\mathrm{C}$ virus infection. Hepatol Res, 44, 137-44.

Singal AG, Manjunath H, Yopp AC, et al (2014). The effect of PNPLA3 on fibrosis progression and development of hepatocellular carcinoma: a meta-analysis. The American journal of gastroenterology, 109, 325-34.

Smagris E, BasuRay S, Li J, et al (2015). Pnpla3I148M knockin mice accumulate PNPLA3 on lipid droplets and develop hepatic steatosis. Hepatology, 61, 108-18.

Sookoian S, Castano GO, Burgueno AL, et al (2009). A nonsynonymous gene variant in the adiponutrin gene is associated with nonalcoholic fatty liver disease severity. $J$ Lipid Res, 50, 2111-6.

Sopipong W, Tangkijvanich P, Payungporn S, et al (2013). The KIF1B (rs17401966) single nucleotide polymorphism is not associated with the development of HBV-related hepatocellular carcinoma in Thai patients. Asian Pac J Cancer Prev, 14, 2865-9.

Stickel F, Buch S, Lau K, et al (2011). Genetic variation in the PNPLA3 gene is associated with alcoholic liver injury in caucasians. Hepatology, 53, 86-95.

Takeuchi Y, Ikeda F, Moritou Y, et al (2013). The impact of patatin-like phospholipase domain-containing protein 3 polymorphism on hepatocellular carcinoma prognosis. $J$ Gastroenterol, 48, 405-12.

Tangkijvanich P, Hirsch P, Theamboonlers A, et al (1999). Association of hepatitis viruses with hepatocellular carcinoma in Thailand. J Gastroenterol, 34, 227-33.

Trepo E, Guyot E, Ganne-Carrie N, et al (2012). PNPLA3 (rs738409 $\mathrm{C}>\mathrm{G}$ ) is a common risk variant associated with hepatocellular carcinoma in alcoholic cirrhosis. Hepatology, $\mathbf{5 5}, 1307-8$.

Trepo E, Nahon P, Bontempi G, et al (2014). Association between the PNPLA3 (rs738409 $\mathrm{C}>\mathrm{G}$ ) variant and hepatocellular carcinoma: Evidence from a meta-analysis of individual participant data. Hepatology, 59, 2170-7.

Trepo E, Pradat P, Potthoff A, et al (2011). Impact of patatinlike phospholipase-3 (rs738409 $\mathrm{C}>\mathrm{G}$ ) polymorphism on fibrosis progression and steatosis in chronic hepatitis $\mathrm{C}$. Hepatology, 54, 60-9.

Valenti L, Motta BM, Soardo G, et al (2013). PNPLA3 I148M polymorphism, clinical presentation, and survival in patients with hepatocellular carcinoma. PLoS One, 8, 75982.

Vigano M, Valenti L, Lampertico P, et al (2013). Patatin-like phospholipase domain-containing 3 I148M affects liver steatosis in patients with chronic hepatitis B. Hepatology, 58, 1245-52.

Yuan X, Waterworth D, Perry JR, et al (2008). Population-based genome-wide association studies reveal six loci influencing plasma levels of liver enzymes. Am J Hum Genet, 83, 520-8.

Zampino R, Coppola N, Cirillo G, et al (2015). Patatin-Like Phospholipase Domain-Containing 3 I148M variant is associated with liver steatosis and fat distribution in Chronic Hepatitis B. Dig Dis Sci. 